\title{
Structural Characterization of Functional Compositions Isolated from Dioscorea Purpurea (Cultivar of Ming-Chien) by Raman Spectroscopy
}

\author{
Chih-Hsien Wang ${ }^{1}$, Ming-Jane Chen ${ }^{1}$, Chin-Yin Tseng ${ }^{2}$, Kuo-Min Wei ${ }^{3}$ and Wenlung Chen ${ }^{1 *}$ \\ ${ }^{1}$ Department of Applied Chemistry, National Chiayi University, 300 University Road, Chiayi, 60004, Taiwan \\ ${ }^{2}$ Department of Health Food, Chung Chou University of Science and Technology, Yuanlin Township, Changhua County, 510, Taiwan \\ ${ }^{3}$ Analytical Divisions, Refining and Manufacturing Research Institute, Chinese Petroleum Corporation, Chiayi, Taiwan
}

\begin{abstract}
The structure of functional compositions isolated from $D$. purpurea (Cultivar of Ming-Chien) was characterized by FT-Raman. After serial isolation and purification, functional compositions of $D$. purpurea including allantoin, anthocyanin, $\beta$-carotene, lecithin, and dioscorin were identified. The shiny crystalline of allantoin was stable enough to tolerate with dramatic change in $\mathrm{pH}$ as evidenced by the consistency of FT-Raman spectra. Spectroscopic results indicated that anthocyanin was responsible for the distinguished purple coloration in $D$. purpurea. A very small quantity of egg-yolklike compound extracted by hexane was identified as a mixture of $\beta$-carotene and lecithin Raman stretching of amide I at $1668 \mathrm{~cm}^{-1}$ and amide III at $1241 \mathrm{~cm}^{-1}$ indicated that the structure of dioscorin, the major storage protein in yams, was mostly in anti-parallel $\beta$-sheet. And a slightly conformational difference in the protein structure was detected when the protein was treated with acetone and alcohol, respectively.
\end{abstract}

Keywords: FT-Raman; Anthocyanin; Allantoin; $\beta$-carotene; Lecithin; Dioscorin

\section{Introduction}

Looking for new ways to stay health or fight diseases, people have embraced the versatile functions of herbal medicines. Among thousands of folk medicinal ingredients, yam, the tuber of Dioscorea $s p$., is well known for its multifaceted biological functions. Yam exhibits nutritional superiority compared to other tropical root crops [1]. In addition to being an important staple food in many tropical countries $[2,3]$ yam receives wide attention due to its functional properties and pharmaceutical potential. In a Chinese society, yams are not only served as a health food but are also used as an important ingredient in Chinese herbal medicines. Yam is believed to have a hypoglycemic effect [4] and promote the health of elderly women [5,6]. Yam extracts show antioxidative activity and modified serum lipid levels in human $[7,8]$. Araghiniknam et al. reported that both dehydroepiandrosterone sulfate (DHEA) and the steroid yam extract, dioscorea, have significant activities as antioxidant to modify serum lipid levels [9]. Hou et al. $[10,11]$ and Hsu et al. [12] show that dioscorin, the storage protein of yam tube, purified from various species of yams exhibits versatile enzymatic activity and antioxidant properties. Chinese yam exhibited antioxidative effects in hyperhomocysteinemia rats [13].

Yam (Dioscoreasp.,Dioscoreaceae) isclassified as monocotyledonous but is considered to be closely related to dicotyledonous plants as a second cotyledon remains undeveloped in the embryo [14,15]. A number of yam species have been grown in the world. In previous studies, we showed that different yam cultivars behaved differently in protein composition/structure [16] and antioxidant property [17]. The purple cultivar of $D$. purpurea (Figure 1) was distinguished in pigmentation, antioxidant property, and protein structure. However, there remains rare information about the functional composition of this purple cultivar to date, even less for molecularly structural characterization. We report here for the first time about structural characterization of the functional composition of $D$. purpurea by nearinfrared Fourier transform Raman spectroscopy.

Raman spectroscopy is well known for its capability of providing rich molecular information. The application of conventional dispersive Raman technique in studying pigment-rich plant is usually hampered by strong fluorescence signals arising from the intrinsic chromophore/ fluorphore of natural pigments in plants [18-20]. Different techniques such as resonance Raman, micro-Raman, surface-enhanced Raman scattering, coherence anti-stoke Raman spectroscopy, FT-Raman, etc. have been approached to relax fluorescence problems. Accompanying with near infrared excitation and the high throughput and multiplex characteristics of Michelson interferometer, FT-Raman is capable to overcome fluorescence interference [21-24]. Application of FT-Raman spectroscopy in natural carotenoid has been demonstrated [25]. Cîntă Pînzaru et al. [26] and Rösch et al. [27] successfully demonstrated Raman techniques in the identification and characterization of Lamiaceae plants and pharmaceuticals. Schrader and coworkers presented non-destructive analysis of plants cell and tissues [28]. Accordingly, FT-Raman might serve a good way to study the functional composition in the purple cultivar of $D$. purpurea. After isolation, the functional compositions including allantoin, anthocyanin, EYLC, and dioscorin in D. purpurea were successfully characterized by FT-Raman.

\section{Materials and Methods}

Fresh yam tuber of $D$. purpurea was purchased from a local agricultural cultivation station (Ming-Chien, Taiwan). The tuber is cylindrical in shape with a purple flesh (Figure 1). Ammonium sulfate, acetone, allontoin, hydrochloric acid, hexane, and Tris- $\mathrm{HCl}$ were from Sigma Chem. Co. (St. Louis, MO). Cyanidin chloride was ordered from Extrasynthese (Genay Cedex, France). Alcohol was obtained from Taiwan Wine \& Tobacco Co (Chiayi, Taiwan). All the chemicals were reagent grade. Aqueous solutions were prepared with ultra pure water, from an EASY pure RF-Compact ultrapure water system (Barnstead/ Thermolyne, Dubuque, IW).

*Corresponding author: Wenlung Chen, Department of Applied Chemistry, National Chiayi University, 300 University Road, Chiayi, 60004, Taiwan, Tel: 886-5271-7965; Fax: 886-5-271-7901; E-mail:wlchen@mail.ncyu.edu.tw

Received June 26, 2013; Accepted July 23, 2013; Published July 30, 2013

Citation: Wang CH, Chen MJ, Tseng CY, Wei KM, Chen W (2013) Structura Characterization of Functional Compositions Isolated from Dioscorea Purpurea (Cultivar of Ming-Chien) by Raman Spectroscopy. Nat Prod Chem Res 1: 110 doi:10.4172/ 2329-6836.1000110

Copyright: $\odot 2013$ Wang $\mathrm{CH}$, et al. This is an open-access article distributed under the terms of the Creative Commons Attribution License, which permits unrestricted use, distribution, and reproduction in any medium, provided the original author and source are credited. 


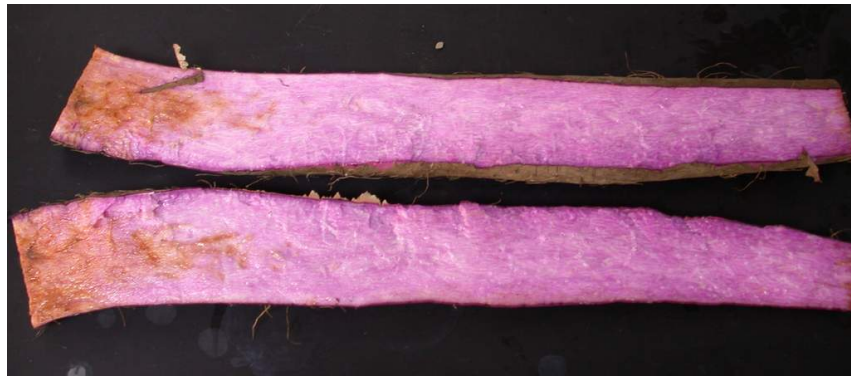

Figure 1: Photograph of $D$. purpurea.

\section{Isolation of functional compositions from $D$. purpurea}

Isolation of functional compositions of $D$. purpurea was referring to previous studies on colorful plants such as cereal grains, grapes, and sweet potatoes with some modifications [29-34]. The process was demonstrated in Figure 2. Yam tubers were washed with water, peeled, chopped into pieces, and put into five fold volumes of acetone or alcohol solution. After maceration and centrifugation, the pomace was separated into two portions, coagulate/aggregate and purple solution. The coagulate/aggregate was collected and homogenized with tenfold volume (w/v) of $50 \mathrm{mM}$ Tris- $\mathrm{HCl}$ buffer $(\mathrm{pH} \mathrm{8.3)}$ and centrifuged at $15000 \mathrm{rpm}\left(4^{\circ} \mathrm{C}\right)$ for $20 \mathrm{~min}$. After centrifugation, the upper layer solution containing crude yam protein was salted out with 0 to $70 \%$ ammonium sulfate. The crude protein precipitated from ammonium sulfate solution was dialyzed against deionized water, lyophilized, and saved for further usage. The purple solution was filtered, collected, and concentrated by a rotary evaporator (LABOROTA 4000 OBdigit, Heidolph Co, Germany) to almost dryness that dark purple residues were spreaded on the flask wall. Aliquots of deionized $\mathrm{H}_{2} \mathrm{O}$ were used to re-dissolve the purplish residues following with 5 folds volume of acetone solution. Very small quantity of yellowish oil-like compound was floated on the surface. $50 \mathrm{~mL}$ hexane was then added into the aqueous acetone solution to extract the yellowish oil-like compounds. The extraction process was repeated at least three times and the hexane extracts were put together, which were evaporated to remove hexane, and a very small amount of sticky and yellowish egg-yolk-like compound (EYLC) was collected and subjected to structural characterization by FT-Raman spectroscopy. Meanwhile, the lower portion of acetone solution was kept in a refrigerator $\left(4^{\circ} \mathrm{C}\right)$ overnight. Some shiny crystalline were precipitated which was filtered out and collected for further study. The acetone filtrate was further concentrated and re-dissolved with deionized $\mathrm{H}_{2} \mathrm{O}$. More crystalline would precipitate as the aqueous solution was stored in $4^{\circ} \mathrm{C}$ refrigerator, which was filtered, collected, and put together with previous one. The aqueous filtrate with deep purple color was then freeze-dried and collected as crude anthocyanin.

Crude anthocyanin was further purified by HPLC equipment. The purification of anthocyanin was carried out on a RP-18GP column (4.6 mm i.d. $\times 250 \mathrm{~mm}$ ) (TosoHaas, Japan) loaded on a Hitachi D-7000 HPLC system (Hitachi, Ltd., Tokoy, Japan). The system was equipped with a Model L-7100 pump, a Model L-7420 UV-VIS detector, and a Rheodyne Model 7725 injector. Peaks were detected at wavelength $530 \mathrm{~nm}$, and acquisition and processing of data were completed by Hitachi B-7000 software with A/D interface. $4 \%$ phosphoric acid and acetonitrile $(85: 15, \mathrm{v} / \mathrm{v})$ driven by the pump system was prepared as mobile phase. Mobile phase was degassed with Branson 2510 ultrasonic system (Branson Ultransonic Corporation, Danbury, CT) right before employing. Aliquots $(10 \mu \mathrm{L})$ of the filtered sample were injected in the chromatographic system. A typical analysis could be completed in 30 minutes with the flow rate of $1.0 \mathrm{mLmin}^{-1}$. Both HPLC-purified anthocyanin and shiny crystal compound were characterized by FTRaman spectroscopy. Photometric analysis of anthocyanin at different $\mathrm{pH}$ was performed on a spectrophotometer (Lambda 40, Perkin Elmer, Wellesley, MA).

\section{Identification of allantoin isolated from $D$. purpurea}

To identify the shiny crystalline compound precipitated from acetone-extracted solution mentioned above, element analysis and physical properties such as melting point and solubility of this compound were carried out. The crystal compound was fairly soluble in hot water but insoluble in cold water. After recrystalization from water the melting point of the compound was determined by a MelTemp II (Laboratory Devices, Holliston, MA). Elemental analysis was performed by an Heraeus CHN-O-S Rapid Elemental Analyzer (Elemental Vario EL III, Germany), which was kindly supported from the Central Instrument Center of National Science Counsil of Taiwan located at National Chung Hsing University. For analyzing the content of $\mathrm{C}, \mathrm{H}$, and $\mathrm{O}$ in the crystal compound, $1.760 \mathrm{mg}$ and 1.800 $\mathrm{mg}$, respectively, of sample were filled in a tin-made container and put in the $1150^{\circ} \mathrm{C}$ combustion chamber. With the aid of tin, the heating temperature rise up to $1800^{\circ} \mathrm{C}$, at which sample could be completely burned and turned into $\mathrm{CO}_{2}, \mathrm{H}_{2} \mathrm{O}$, and $\mathrm{NO}_{2}$. After being reduced by $\mathrm{Cu}$, the mixture product of $\mathrm{CO}_{2}, \mathrm{H}_{2} \mathrm{O}$, and $\mathrm{NO}_{2}$ was separated and detected by Thermally Conductive Detector (TCD). After data processing, the weight percentage of $\mathrm{C}, \mathrm{H}$, and $\mathrm{O}$ was determined. For oxygen analysis, sample was mixed with graphite, which was burned into $\mathrm{CO}$ at $1100^{\circ} \mathrm{C}$. The content of $\mathrm{CO}$ was determined via TCD detector. Elemental percentages of the crystal compound are: C, 30.28, 30.36; N, 36.48, $36.50 ; \mathrm{H}, 3.90,3.81 ; \mathrm{O}, 28.93,28.92$. Calculated (theoretical) values for allantoin are: $\mathrm{C}, 30.39 ; \mathrm{N}, 35.44 ; \mathrm{H}, 3.81 ; \mathrm{O}, 30.38$.

\section{HPLC/ESI-MS analysis of anthocyanin from D. purpurea}

Crude anthocyanin was subjected to be identified by a HPLC/ESIMS system. The HPLC/ESI-MS analysis was performed on an Agilent 1100Series LC/MSD Trap SL system (Agilent Technologies Inc., Palo Alto, CA) equipped with DAD detector and coupled on-line with an ion trap MS/MS spectrometer. The column used was a Zorbax 300A SBC18, $150 \times 3.0 \mathrm{~mm}, 3.5 \mu \mathrm{m}$ particle size (Agilent Technologies Inc., Palo Alto, CA). Crude anthocyanin $\left(2 \mathrm{mg} \mathrm{mL}^{-1}\right)$ was injected directly on the system without further treatment. The HPLC/DAD conditions were: column temperature, $30^{\circ} \mathrm{C}$; column flow rate, $0.3 \mathrm{~mL} \mathrm{~min}^{-1}$; Solvent A: $\mathrm{H}_{2} \mathrm{O}, 0.5 \%$ acetic acid; Solvent B: Methanol, $0.2 \%$ acetic acid; Solvent gradient: Solvent B: $0 \%$ at $0 \mathrm{~min}, 100 \%$ at $20 \mathrm{~min}, 100 \%$ at $25 \mathrm{~min}$; Injection volume: $3 \mu \mathrm{L}$. Electrospray ionization (ESI) was performed in positive ion mode. ESI conditions were: nebulizer pressure, $30 \mathrm{psi}$; drying gas flow and temperature, $8.0 \mathrm{~L} \mathrm{~min}^{-1}$ and $350^{\circ} \mathrm{C}$, respectively; HV capillary, 3500V; scan speed, scan range (m/z):165-1000.

\section{Electrophoresis of yam protein}

Sodium dodecyl sulfate polyacrylamide gel electrophoresis (SDSPAGE) was performed in a vertical mini-gel system (Mini-Protean II Dual Slab Cell, Bio-Rad Lab, Richmond, CA) as described by Laemmli [35] with some modifications. Polyacrylamide gels (5\% stacking and $14 \%$ resolving gel) were formed by co-polymerization of acrylamide and bis-acrylamide with the aid of initiator TEMED and ammonium persulfate. Buffer solutions for the stacking and resolving gels were prepared from $0.125 \mathrm{M}$ Tris- $\mathrm{HCl}(\mathrm{pH} 6.8)$ and $0.375 \mathrm{M}$ Thris- $\mathrm{HCl}(\mathrm{pH}$ $8.9)$, respectively, incorporating with $0.1 \%$ SDS. The running buffer $(\mathrm{pH}$ 8.6) consisted of $0.1 \%$ SDS, $0.1 \% 2$-mercaptoethanol, $0.19 \mathrm{M}$ glycine, 
$0.025 \mathrm{M}$ Tris- $\mathrm{HCl}$, and $1 \mathrm{mM}$ EDTA. The sample buffer was composed of $0.1 \%$ SDS buffer, $10 \%$ sucrose, $0.05 \%$ bromophenol blue and $20 \mathrm{mM}$ dithiothreitol. Samples $(10 \mu \mathrm{L})$ were well-mixed with the sample buffer by a microcentrifuge at $1200 \mathrm{rpm}$ (Hettich $\mathrm{GmbH} \&$ Co., Tuttlingen, Germany) and heated at $100^{\circ} \mathrm{C}$ in a Dry-Bath (Dubuque, Iowa, USA) for 3 minutes prior to being loaded to the gels. Electrophoresis was carried out with a fixed voltage of $180 \mathrm{~V}$ for 55 minutes. After electrophoresis, the gel was stained with $0.25 \%$ Coomassie Brilliant blue solution containing $12.5 \%$ trichloroacetic acid, $20 \%$ methanol, and $7.0 \%$ acetic acid for 20 minutes and destained with a solution of $20 \%$ methanol and $7.0 \%$ acetic acid overnight. Procedures for non-reducing SDS-PAGE electrophoretic analysis were same to the one under reducing conditions described above except for the absence of reducing agents such as 2-mercaptoethanol and dithiothreitol in sample and electrophoretic buffer solutions. Protein markers for reduced SDS-PAGE were myosin $(203 \mathrm{kDa}), \beta$-galactosidase $(120 \mathrm{kDa})$, phosphorylase b $(97.6 \mathrm{kDa})$, bovine serum albumin $(90 \mathrm{kDa})$, ovalbumin $(51.7 \mathrm{kDa})$, carbonic anhydrase $(34.1 \mathrm{kDa})$, soybean trypsin inhibitor $(28.0 \mathrm{kDa})$, lysozyme $(20.0 \mathrm{kDa})$ and aprotinin $(6.4 \mathrm{kDa})$.

\section{FT-Raman measurement}

FT-Raman measurements were performed by using a Bruker RFS100 FT-spectrophotometer (Bruker Optik GmbH, Lubeck, Germany). Sample collected from the isolation processes described above was put onto a stainless steel holder for Raman measurement. A continuous wave Nd-YAG laser (Coherent Lubeck GmbH, Lubeck, Germany) with wavelength $1064 \mathrm{~nm}$, pumped by diode laser, was used as the near infrared Raman excitation source. A He-Ne laser beam was overlapped with $1064 \mathrm{~nm}$ beam in order to visualize the Raman sampling spot. The laser light with power of $150 \mathrm{~mW}$ was introduced and focused on the sample. The scattered radiation was collected at $180^{\circ} \mathrm{C}$ with an ellipsoidal mirror and was filtered, modulated and reflected back into the highly sensitive GaAs detector that was cooled by liquid nitrogen. Raman spectra were produced over the Raman shift $0-3500 \mathrm{~cm}^{-1}$. Typically, 200 500 interferograms, depending on sample characteristics, were coadded at $4 \mathrm{~cm}^{-1}$ resolution with a sampling time from 7 to 15 minutes. Each numerical calculation of the Raman intensity ratio was based on the average of triplicate measurements at least.

\section{Results and Discussion}

Figure 2 illustrated the isolation of the functional compositions in D. purpurea. Acetone or alcohol is usually used to extract anthocyanin from pigment-rich plants, particularly under acidic milieus [29-37]. And because yam is rich in viscous mucilage, the aqueous extract would become too sticky to pass through filter paper if aqueous buffer was directly used for massive extraction. Hence, acetone or alcohol was chosen to extract functional compositions from D. purpurea. As shown in the scheme, protein would precipitate after homogenization and centrifugation, while other functional compounds including anthocyanin, allantoin, and yellowish egg-yolk-like compound remain left in the extract. After concentrating, the filtrate became thicker and stuck onto flask wall. A small volume of deionized $\mathrm{H}_{2} \mathrm{O}$ was applied to wash out the concentrated residues which were further extracted with acetone/hexane solution. The yellowish and viscous EYLC was extracted by hexane and anthocyanin and allantoin remained in the aqueous acetone solution. After serials crystallization, filtration, and concentrate as demonstrated in Figure 2, both allantoin and anthocyanin were isolated, separately. Identification and characterization of each functional compound were carried out by elemental analysis, HPLC/ ESI/MS, UV/Vis, and FT-Raman as described below.

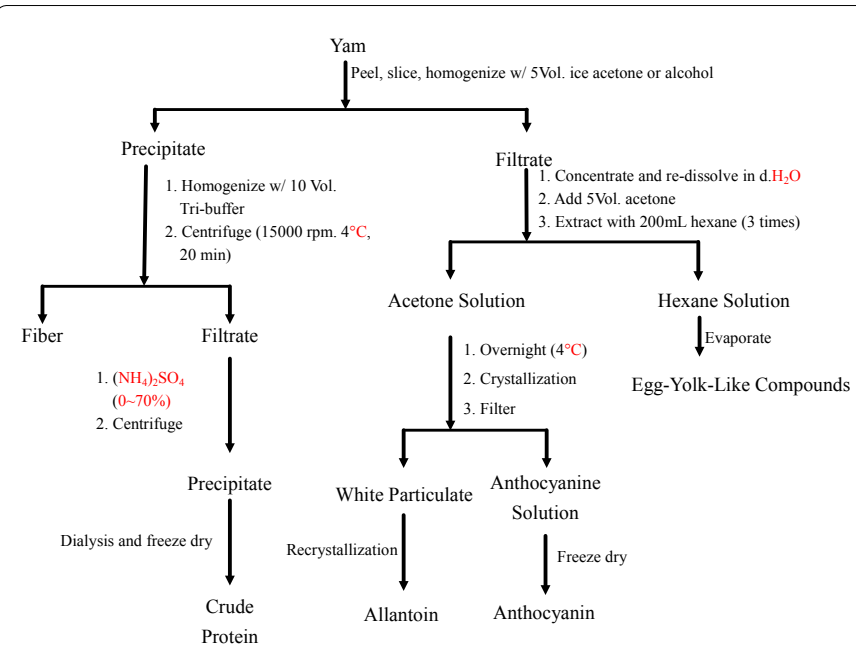

Figure 2: Scheme for the isolation of functional compositions from $D$. purpurea.

\section{Identification and characterization of allantoin}

When acetone extract was stored in a refrigerator, a clear, transparent and prism-like compound was crystallized. To identify this compound, determination on physical property such as melting point (m.p.), solubility, and element analysis were carried out. All results: m.p., 225.0 \pm 2.0; molecular formula, $\mathrm{C}_{4} \mathrm{H}_{6} \mathrm{~N}_{4} \mathrm{O}_{3}$; low solubility in aqueous but easily dissolved in hot water; pointed out that the crystalline belonged to an allantoin. Figure 3 showed FT-Raman spectra of a commercial allantoin and the isolated one. Both spectra, Figure $3 \mathrm{a}$ and $3 \mathrm{~b}$, were indistinguishable, which further confirmed that the crystalline was an allantoin. This is consistent with previous studies that allantoin represents the major component of nonprotein nitrogen in sweet potato and yam [38,39]. Figure 4 demonstrated FT-Raman spectra of allantoin at $\mathrm{pH} 3,7.6$, and 11, respectively. The consistency of FT-Raman spectra indicates that the structure of allantoin is rather stable for enduring with wide range of $\mathrm{pH}$ variation. The remarkable stability of allantoin may play a positive role in its multitudinous bio-functions: enhancing the growth of skin cell, being employed as an anti-ulcer medicine and an anti-inflammatory medicine, serving as the popular raw material of high-grade cosmetics because of its good effects in light prevention, sterilization, antisepticising, deodorization and anti-oxidation.

\section{Isolation and identification of anthocyanins from $D$. purpurea}

Anthocyanin is usually responsible for most coloration in plants, it may play important role in expressing the unique purple color of $D$. purpurea. Figure 5 displayed UV-Vis spectrum of anthocyanin isolated from D. purpurea. Absorption bands around 520 550 and 280 320 nm are due to the resonance absorbance of benzopyrylium and 2-phenyl groups, respectively, which are typical pattern of anthocyanin. This clearly indicated that anthocyanin was responsible for the purple color of $D$. purpurea. The purple color of the isolated anthocyanin exhibits unusually stable as exposing to sunlight. This is consistent with Yoshida's result that an unusually stable monoacylated anthocyanin, alatanin C, was found in a purple yam Dioscorea alata [36]. Figure 6 displayed FT-Raman spectra of the isolated anthocyanin (Figure 6a) and a commercial cyanidin chloride (Figure 6b). By comparing both spectra, it is clear that cyanidin constitutes the major aglycon of anthocyanins in D. purpurea. The lines present in the range of $1400-1660 \mathrm{~cm}^{-1}$ are due to ring stretching vibrational modes, $v(C C)$. The Raman spectrum in the $1100-1400 \mathrm{~cm}^{-1}$ region illustrates the substitute modes in the benzene rings. A little difference between the Raman profile of Figure $6 \mathrm{a}$ and $6 \mathrm{~b}$ is reasonable because 


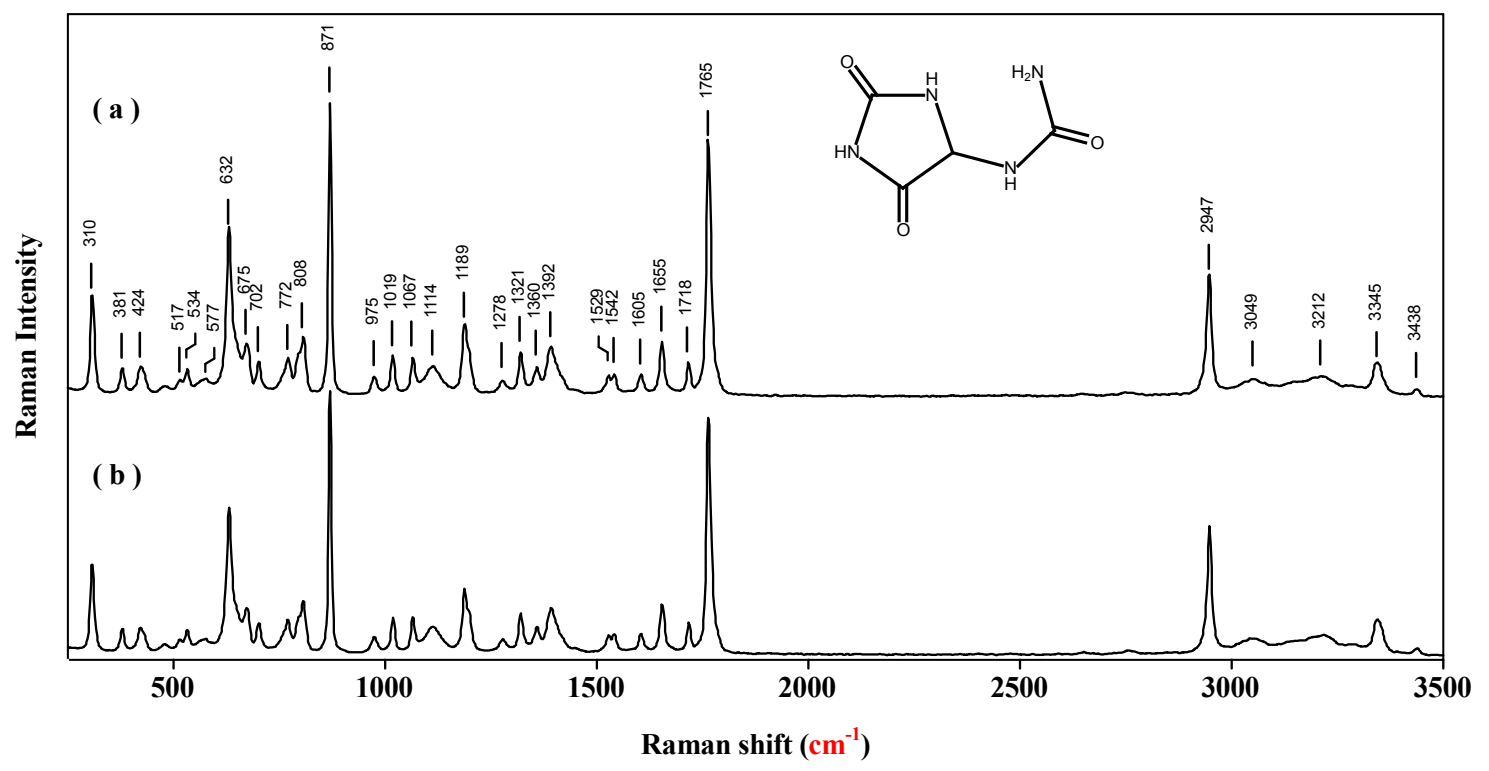

Figure 3: FT-Raman spectra in 350 3500 $\mathrm{cm}^{-1}$ region of allantoin (a) commercial allantoin standard. (b) isolated from D. purpurea. Data acquisition conditions: excitation wavelength $=1064 \mathrm{~nm}$; laser power $=150 \mathrm{~mW}$; spectral resolution $=4.0 \mathrm{~cm}^{-1}$, and coadded scan $=200(\sim 7 \mathrm{~min})$.

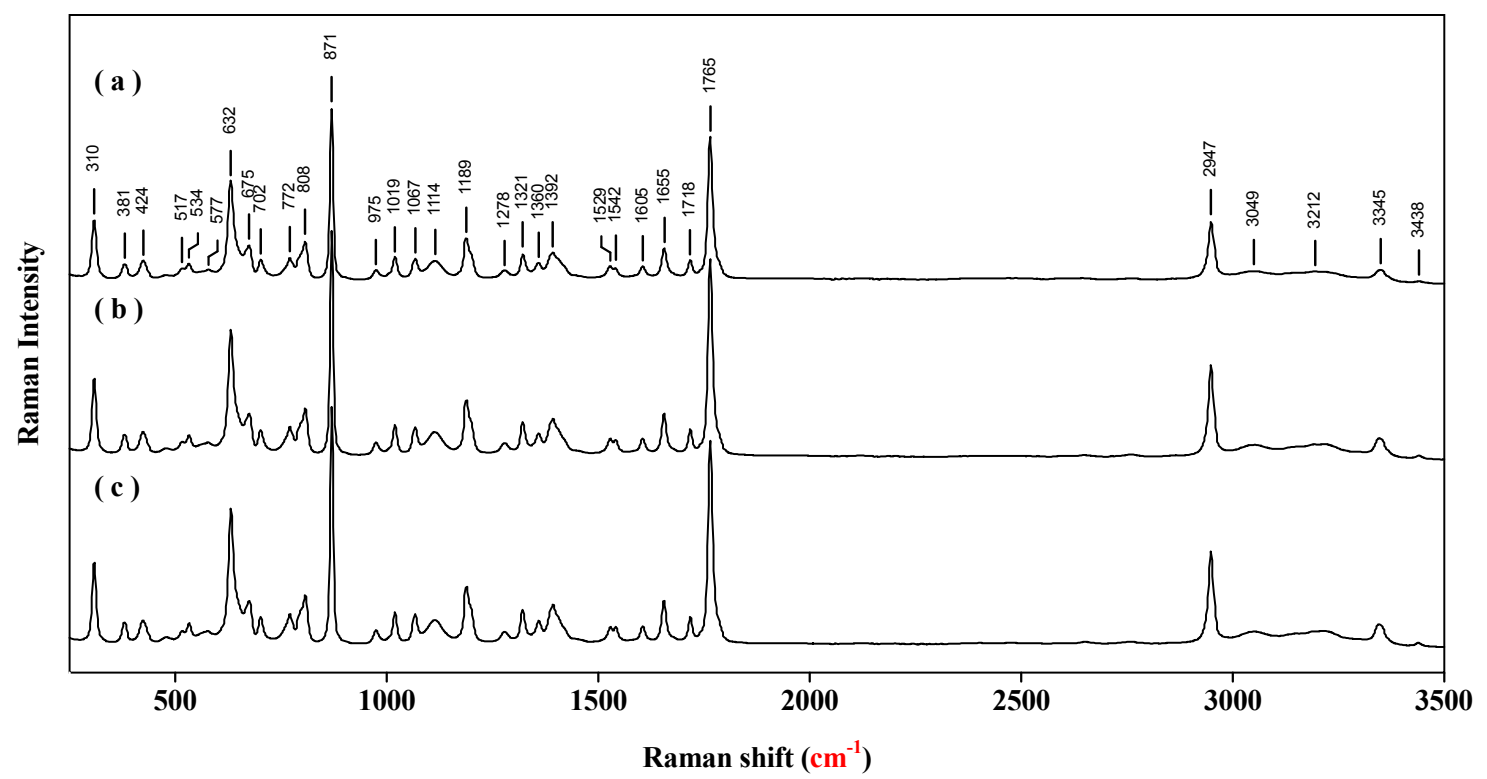

Figure 4: FT-Raman spectra in 350 3500 $\mathrm{cm}^{-1}$ region of allantoin isolated from $D$. purpurea at (a) $\mathrm{pH} 11$ (b) $\mathrm{pH} 7.6$ (c) $\mathrm{pH} 3$. Data acquisition conditions: excitation wavelength $=1064 \mathrm{~nm}$; laser power $=150 \mathrm{~mW}$; spectral resolution $=4.0 \mathrm{~cm}^{-1}$, and coadded scan $=200(\sim 7 \mathrm{~min})$.

the compound extracted from $D$. purpurea is an anthocyanin molecule which is composed of aglycone, sugar residues, and some organic acids, while commercial cyanidin merely represents an aglycone. The spectral difference may result from the interaction of sugar residues, organic acids and aglycone in anthocyanin. As mentioned before, the application of Raman spectroscopy for anthocyanin is usually hampered by the strong fluorescence interference arising from the intrinsic pigmentation in anthocyanin. To further identify the composition of anthocyanin in $D$. purpurea, a preliminary analysis of the crude anthocyanin was performed by HPLC coupled with mass spectrometry (LC-MS), which recently has been developed as one of the most powerful tool for identify unknown anthocyanin in plants [37]. Figure 7A and 7B showed the chromatographic profile of isolated anthocyanin detected by UV $(530 \mathrm{~nm})$ and mass detector, respectively. Referring to Yoshida's work [36], the major peak ( $\left.\mathrm{R}_{\mathrm{t}}: 13.1\right)$ with $\mathrm{m} / \mathrm{z}$ ratio of 817 was due to the association of cyanidin with sinapic acid and hexose; i.e., the anthocyanin in D. purpurea is composed of an acylated cyanidin. This could be further confirmed via the collision mechanism of tandem mass. As displayed in Figure 7C, the parent ion with $m / z=287$ clearly proved that cyanidin (Mw. 287) was the major aglycone in $D$. purpurea. The fragment of $m / z=530(\mathrm{~m} / z=817-287)$ is due to the combination of a sinapic acid $(\mathrm{m} / \mathrm{z}=206)$ with two molecules of hexose such as glucose $(m / z=324)$. Further study by NMR spectroscopy (COSY) is needed to understand the attachment position of the sinapic acid to the aglycone and the position of sugar moieties as well as the interlinkage. 


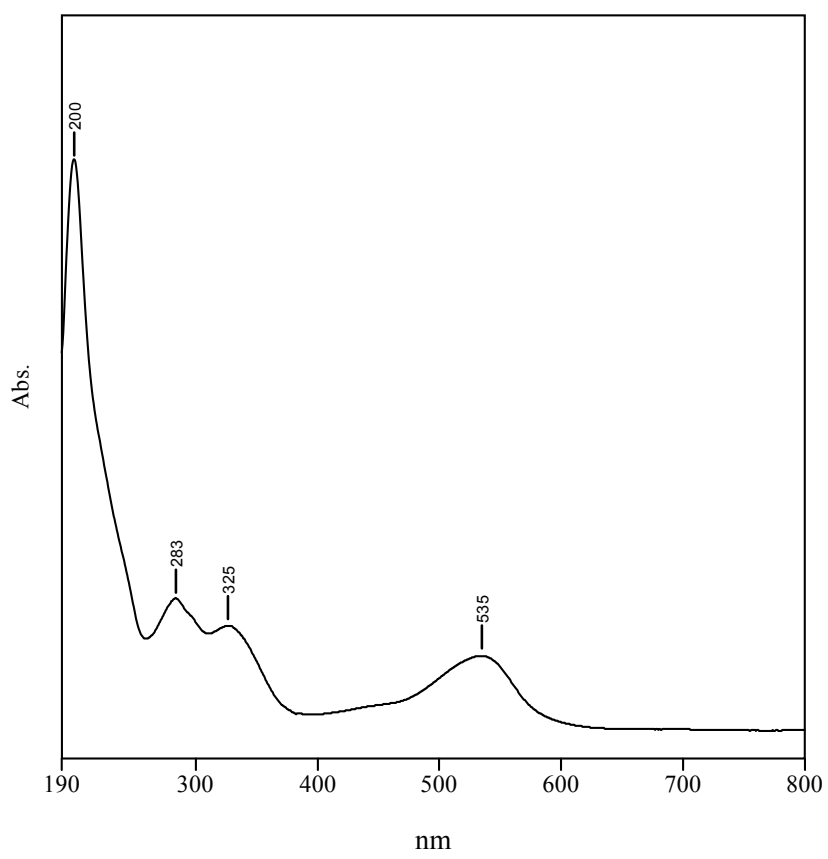

Figure 5: UV-Vis absorbance of anthocyanin isolated from $D$. purpurea.

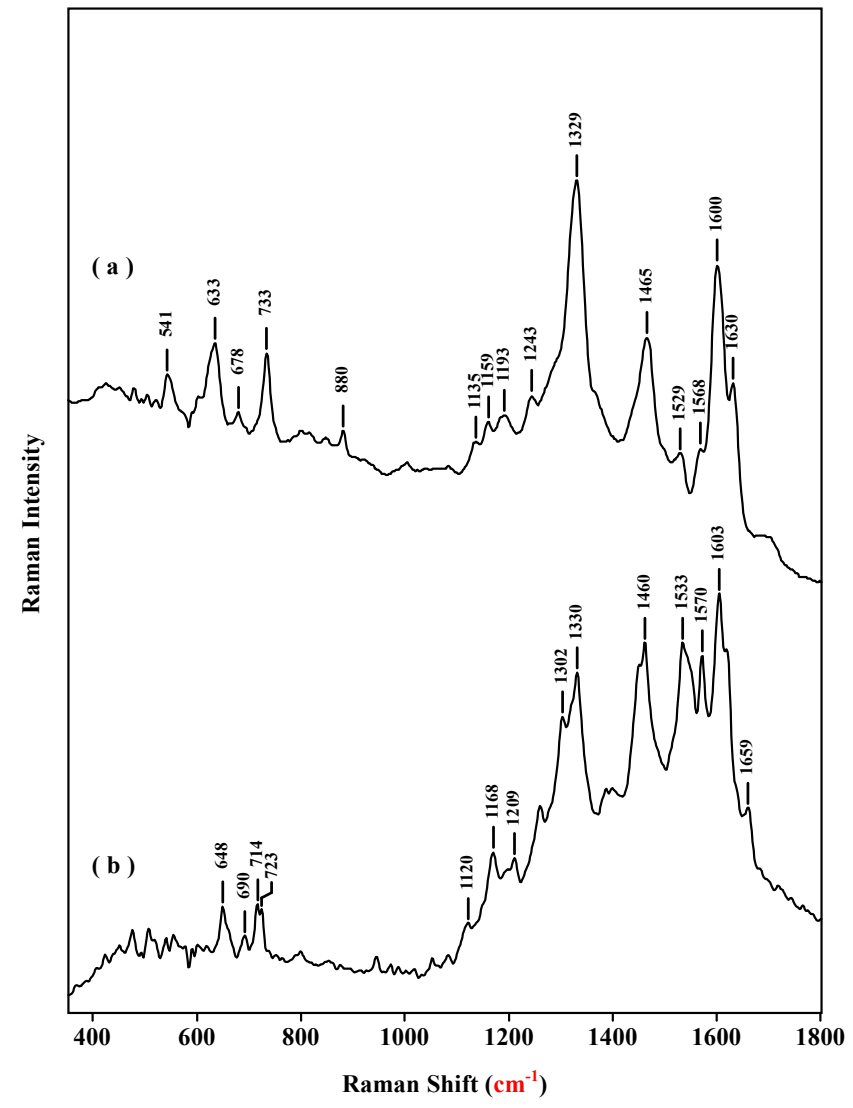

Figure 6: FT-Raman spectra in $350 \sim 1800 \mathrm{~cm}^{-1}$ region of anthocyanin (a) isolated from $D$. purpurea (b) commercial cyanidin standard. Data acquisition conditions: excitation wavelength $=1064 \mathrm{~nm}$; laser power $=150 \mathrm{~mW}$; spectral resolution $=4.0 \mathrm{~cm}^{-1}$, and coadded scan $=500$

\section{Analysis of egg-yolk-like compounds in D. purpurea}

A small amount of sticky and yellowish compounds extracted by hexane looked like an egg yolk, which is a natural oil-in-water emulsion containing $52 \%$ dry matter that fat represents about $65 \%$, proteins about $31 \%$, and $4 \%$ of carbohydrates, vitamins, and minerals [40]. Literature survey revealed little information on EYLC and the existence in yam tuber before. The oily characteristic of EYLC and very small amount has constraint it from HPLC study. EYLC was then analyzed directly by FT-Raman spectroscopy. Similar to most yellowish pigments in plant, the yellow color of EYLC may result from lightabsorbing chromophores which usually generate strong fluorescence overwhelming Raman signals. With wavelength excitation at 1064 $\mathrm{nm}$, the disturbing fluorescence effect of the yellowish pigment can be avoided; furthermore, FT-Raman spectroscopy coupled with this wavelength excitation may give a strong enhancement for a yellow pigment in plants such as carotenoids due to preresonance effect [25]. Figure 8 showed Raman profile of EYLC (Figure 8a), lecithin (Figure $8 \mathrm{~b}$ ), and $\beta$-carotene (Figure $8 \mathrm{c}$ ). The Raman peak of EYLC matches perfectly to that of lecithin and carotene, (Table 1). Carotenoids can be characterized by Raman vibrational modes $v_{1}\left(1500-1550 \mathrm{~cm}^{-1}\right), v_{2}$ (1150-1170 $\left.\mathrm{cm}^{-1}\right)$, and $v_{3}\left(1000-1020 \mathrm{~cm}^{-1}\right)$ (Figure 8c). The $v_{1}$ and $v_{2}$ modes are due to in-phase $\mathrm{C}=\mathrm{C}$ and $\mathrm{C}-\mathrm{C}$ stretching vibrations of the polyene chain, while $v_{3}$ arises from in-plane rocking modes of $\mathrm{CH}_{3}$ groups attached to the polyene chain and coupled with C-C bonds [25]. Referring to Schulz and coworker's study [25], EYLC presented strong Raman bands at 1526, 1158, and $1006 \mathrm{~cm}^{-1}$ (Figure 8a), which was assigned to $v(\mathrm{C}=\mathrm{C}), v(\mathrm{C}-\mathrm{C})$ and $\tau(\mathrm{CH})_{3}$ of $\beta$-carotene. Some Raman peaks in Figure 8a were consistent with that of lecithin (Figure 8b). Raman peaks, present in both Figure $8 \mathrm{a}$ and $8 \mathrm{~b}$, at $1747,1659,1440$, 1301,1269 , and $1082 \mathrm{~cm}^{-1}$ are characteristic signals of lecithin and are assigned to the $\mathrm{C}=\mathrm{O}$ stretching, $\mathrm{C}=\mathrm{C}$ stretching (cis form), $\mathrm{CH}_{2}$ scissoring, $\mathrm{CH}_{2}$ twisting, $=\mathrm{C}-\mathrm{H}$ in-plane bending, and $\mathrm{C}-\mathrm{C}$ stretching, respectively. Based on Raman results, it implies that EYLC consists of lecithin and carotenoids sharing some nutritional roles for the purple yam cultivar.

\section{Structural characterization of dioscorin of $D$. purpurea}

In Figure 9, the electrophoresis result (SDS-PAGE) showed that the molecular mass of dioscorin subunit, the major storage protein of yam, was about $32 \mathrm{kDa}$ and had no significant change being treated with acetone or alcohol. However, a slightly structural difference in dioscorin was detected by FT-Raman, Figure 10a and 10b, when it was treated with acetone and alcohol, respectively. The secondary structure

\begin{tabular}{|c|c|c|}
\hline EYLC & lecithin & $\boldsymbol{\beta}$-carotene \\
\hline 871 & 874 & 1008 \\
\hline 1006 & & \\
\hline 1065 & 1065 & 1156 \\
\hline 1082 & 1079 & 1190 \\
\hline 1158 & & 1211 \\
\hline 1191 & & \\
\hline 1212 & 1268 & \\
\hline 1268 & 1301 & 1513 \\
\hline 1301 & 1439 & 1586 \\
\hline 1440 & & \\
\hline 1526 & 1658 & \\
\hline 1696 & 1741 & \\
\hline 1740 & & \\
\hline
\end{tabular}

Table 1: Comparison of Raman wave numbers $\left(\mathrm{cm}^{-1}\right)$ among EYLC, lecithin $\beta$-carotene. 

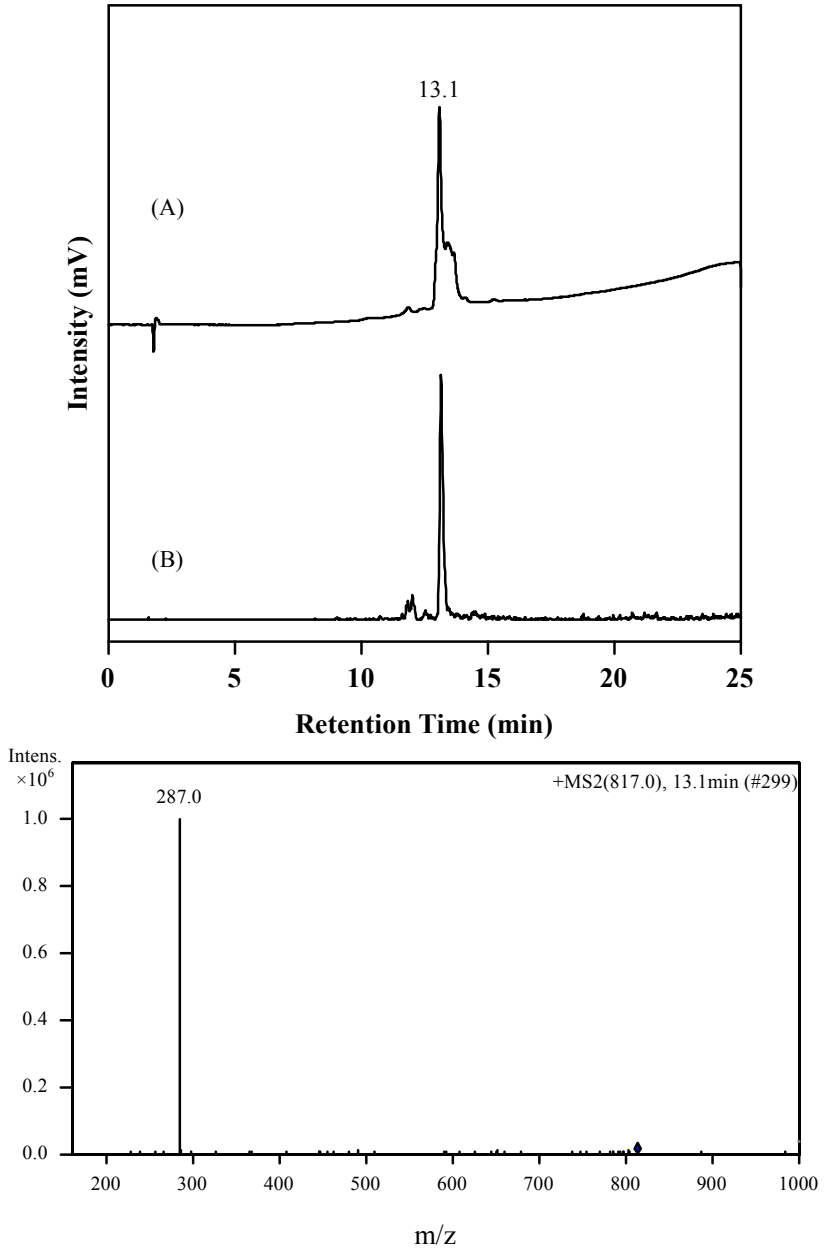

Figure 7: HPLC/ESI-MS analysis of crude anthocyanins isolated from $D$ purpurea (A) HPLC with DAD detector $(530 \mathrm{~nm}$ ) (B) LC/MS/EIC at $817 \mathrm{~m} / \mathrm{z}$ (C) LC/MS/MS with isolation mass: $817 \mathrm{~m} / \mathrm{z}$. Experimental conditions were described in the section of "Material and Methods".

of yam protein of $D$. purpurea was mostly in anti-parallel $\beta$-sheet as evidenced by the amide I at $1669 \mathrm{~cm}^{-1}$ and amide III at $1247 \mathrm{~cm}^{-1}$. The secondary structure of dioscorin experienced little change between acetone- and alcohol-treatment. However, the micro environmental property of major amino acids in yam proteins expressed significant difference, which could be illustrated by the Raman profile in the low frequency range, such as $621 \mathrm{~cm}^{-1}$ for phenylalanine, $643 \mathrm{~cm}^{-1}, 828 \mathrm{~cm}^{-1}$, $853 \mathrm{~cm}^{-1}$ for tyrosine, and $759 \mathrm{~cm}^{-1}$ for tryptophan $[22,41]$. Siamwiza et al. [42] reported that the tyrosine doublet at $850 \mathrm{~cm}^{-1}$ and $830 \mathrm{~cm}^{-1}$ was sensitive to the nature of the hydrogen bond of the phenol hydroxyl group. The intensity ratio of $850 \mathrm{~cm}^{-1}$ to $830 \mathrm{~cm}^{-1}\left(\mathrm{I}_{850 / 830}\right)$ provides a diagnostic of phenolic $\mathrm{OH}$ hydrogen bond of tyrosine in protein. Current result, $\mathrm{I}_{855 / 829}=1.11$ for acetone and $\mathrm{I}_{855 / 829}=0.95$ for alcohol, indicated that the phenolic hydroxyls of tyrosine were on the surface of dioscorin and that tyrosine residues were more accessible to hydrophilic milieus in alcohol solution than in acetone solution. Difference in polarity between acetone and alcohol may affect the conformational arrangement of dioscorin.

In summary, we present here the isolation characterize of functional compositions including anthocyanin, allantoin, EYLC, and dioscorin in the distinctive purple yam cell line (D. purpurea), for the first time.

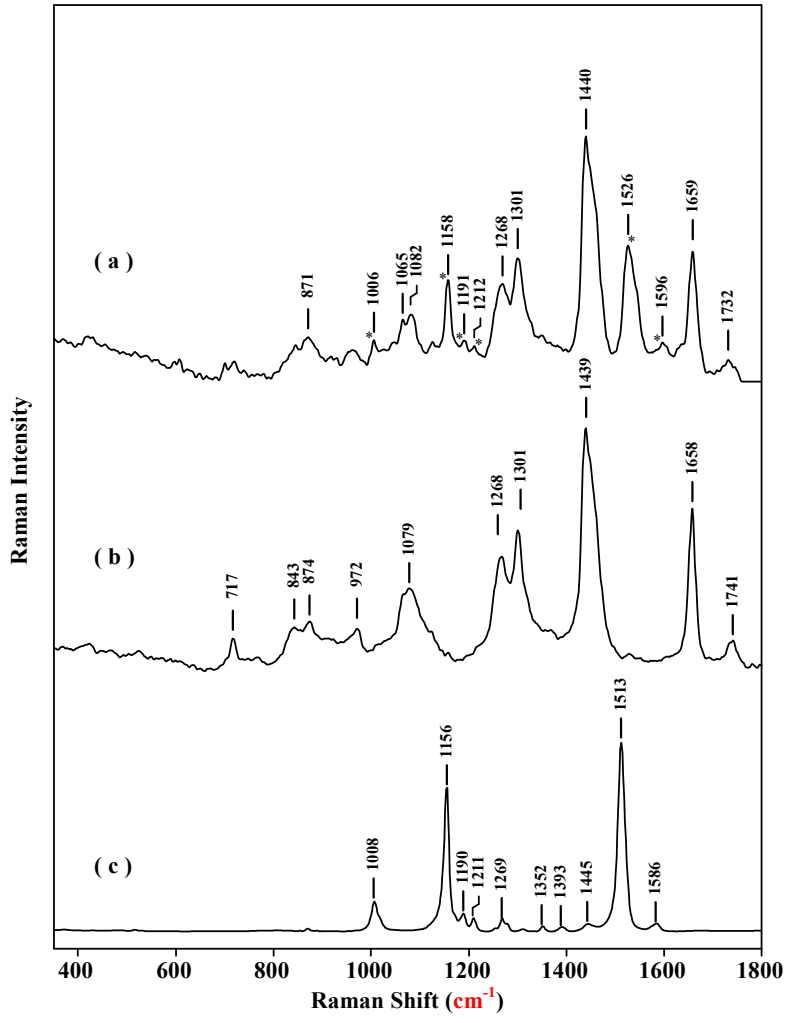

Figure 8: FT-Raman spectrum in $350 \sim 1800 \mathrm{~cm}^{-1}$ region of (a) egg-yolklike compound isolated from $D$. purpurea. (b) Lecithin (c) $\beta$-carotene. Data acquisition conditions: excitation wavelength $=1064 \mathrm{~nm}$; laser power $=150 \mathrm{~mW}$; spectral resolution $=4.0 \mathrm{~cm}^{-1}$, and coadded scan $=200(\sim 7 \mathrm{~min})$.

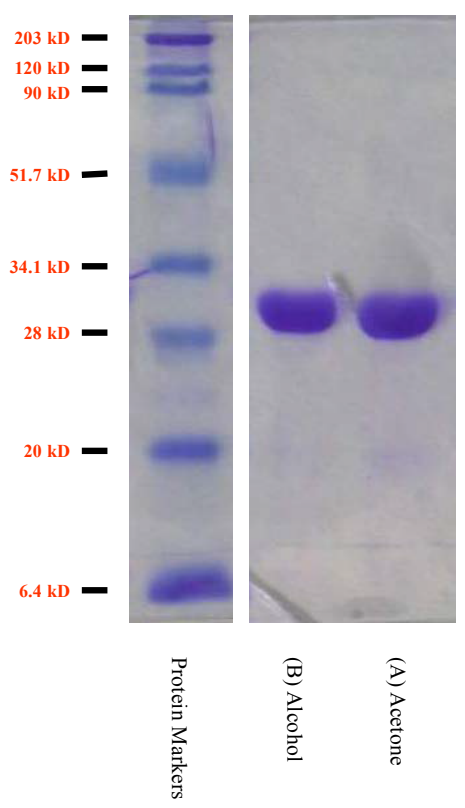

Figure 9: The SDS-PAGE of discorin isolated from $D$. purpurea. The yam proteins were treated with (a) acetone (b) alcohol. Protein markers: myosin (203 $\mathrm{kDa})$ phosphorylase b $(97.6 \mathrm{kDa})$, bovine serum albumin $(90 \mathrm{kDa})$, ovalbumin $(45.0 \mathrm{kDa})$, carbonic anhydrase $(34.1 \mathrm{kDa})$, trypsin inhibitor $(28 \mathrm{kDa})$, lysozyme $(20.0 \mathrm{kDa})$, and aprotinin $(6.4 \mathrm{kDa})$. Electrophoresis was carried out at a constant voltage of $180 \mathrm{~V}$ for 55 minutes. 
Citation: Wang CH, Chen MJ, Tseng CY, Wei KM, Chen W (2013) Structural Characterization of Functional Compositions Isolated from Dioscorea Purpurea (Cultivar of Ming-Chien) by Raman Spectroscopy. Nat Prod Chem Res 1: 110. doi:10.4172/ 2329-6836.1000110

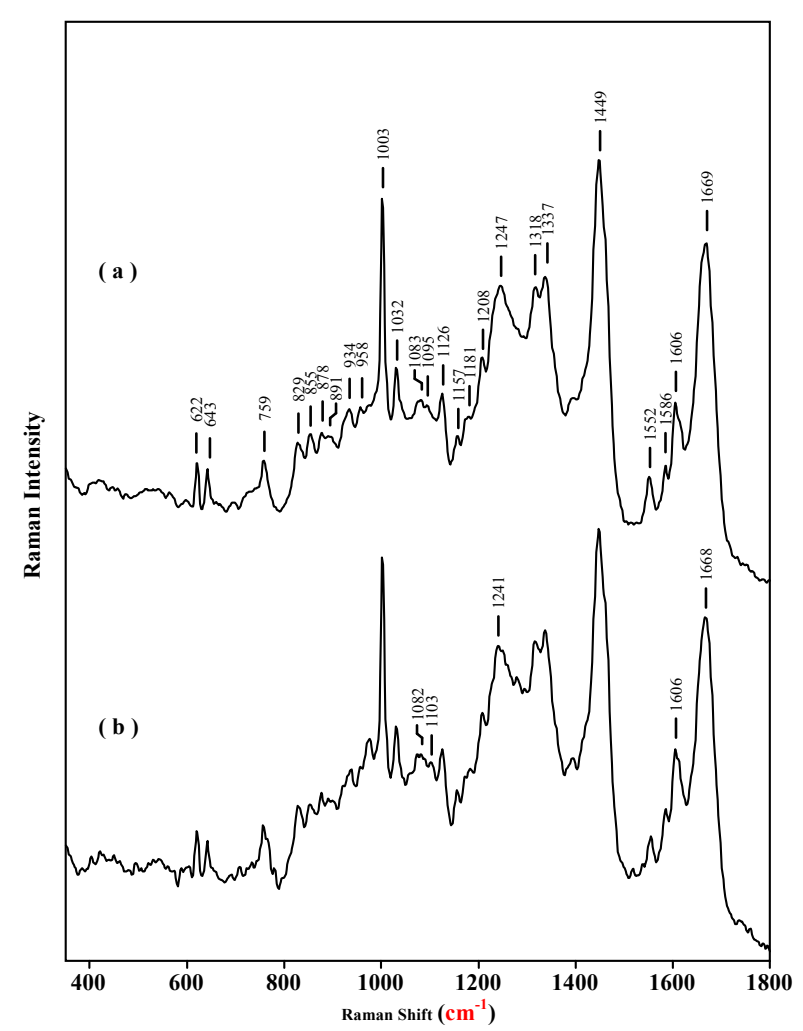

Figure 10: Raman spectra in 350 1800 $\mathrm{cm}^{-1}$ region of dioscorins isolated from D. purpurea. (a) acetone-treated (b) alcohol-treated. Data acquisition conditions: excitation wavelength $=1064 \mathrm{~nm}$; laser power $=150 \mathrm{~mW}$; spectral resolution = $4.0 \mathrm{~cm}^{-1}$, and coadded scan $=500(\sim 15 \mathrm{~min})$.

Anthocyanin with a major aglycon composition of cyanidin was responsible for the purple coloration of this yam cultivar. The presence of anthocyanin, allantoin, EYLC, and dioscorin in D. purpurea may enhance its nutritional and physiological function in addition to being a staple trait. Success in characterizing of chromophore-rich molecules such as anthocyanin, lecithin, and carotenoid in D. purpurea suggests that FT-Raman may be extensively applied to the study of natural pigments.

\section{Acknowledgement}

Financial support (NSC93-2113-M-415-007; NSC942113-M-415-00) from the National Science Council of Taiwan is much appreciated.

\section{References}

1. Wanasundera JP, Ravindran G (1994) Nutritional assessment of yam (Dioscorea alata) tubers. Plant Foods Hum Nutr 46: 33-39.

2. Akanbi CT, Gureje PO, Adeyemi IA (1996) Effect of heat-moisture pre-treatment on physical characteristics of dehydrated yam. J Food Eng 28: 45-54.

3. Omonigho SE, Ikenebomeh MJ (2000) Effect of temperature treatment on the chemical composition of pounded white yam during storage. Food Chem 71 215-220.

4. Hikino H, Konno C, Takahashi M, Murakami M, Kato Y, et al. (1986) Isolation and Hypoglycemic Activity of Dioscorans A, B, C, D, E, and F; Glycans of Dioscorea japonica Rhizophors. Planta Med 52: 168-171.

5. Mirkin G (1991) Estrogen in yams. J Am Med Assoc 265: 912.

6. Djerassi C (1992) Drugs from Third World plants: the future. Science 258: 203
7. Chen HL, Wang CH, Chang CT, Wang TC (2003) Effects of Taiwanese yam (Dioscorea japonica Thunb var. pseudojaponica Yamamoto) on upper gut function and lipid metabolism in Balb/c mice. Nutrition 19: 646-651.

8. Choi EM, Hwang JK (2002) Enhancement of oxidative response and cytokine production by yam mucopolysaccharide in murine peritoneal macrophage. Fitoterapia 73: 629-637.

9. Araghiniknam M, Chung S, Nelson-White T, Eskeison C, Watson RR (1996) Antioxidative activity of dioscorea and dehydroepiandrosterone (DHEA) in older humans. Life Sci 59: 147-157.

10. Hou WC, Chen HJ, Lin YH (2000) Dioscorins from different Dioscorea species all exhibit both carbonic anhydrase and trypsin inhibitor activities. Bot Bull Acad Sin 41: 191-196

11. Hou WC, Lee MH, Chen HJ, Liang WL, Han CH, et al. (2001) Antioxidant activities of dioscorin, the storage protein of yam (Dioscorea batatas Decne) tuber. J Agric Food Chem 49: 4956-4960.

12. Hsu FL, Lin YH, Lee MH, Lin CL, Hou WC (2002) Both dioscorin, the tuber storage protein of yam (Dioscorea alata cv. Tainong No. 1), and its peptic hydrolysates exhibited angiotensin converting enzyme inhibitory activities. J Agric Food Chem 50: 6109-6113.

13. Yang DJ, Lu TJ, Huang LS (2003) Isolation and Identification of Steroida Saponins in Taiwanese Yam Cultivar (Dioscorea pseudojaponica Yamamoto). J Agric Food Chem 51: 6438-6444.

14. Lawton JR, Lawton JRS (1967) The morphology of the dormant embryo and young and young seeding of five species of Dioscorea from Nigeria. Proc Linn Soc, London, 178: 153-159.

15. Lawton JR, Lawton JRS (1969) The development of the tuber in seedlings of five species of Dioscorea from Nigeria. Bot J Linn Soc 62: 223-232.

16. Liao YH, Wang CH, Tseng CY, Chen HL, Lin LL, et al. (2004) Compositional and Conformational Analysis of Yam Proteins by Near Infrared Fourier Transform Raman Spectroscopy. J Agric Food Chem 52: 8190-8196.

17. Hsu CL, Chen W, Weng YM, Tseng CY (2003) Chemical composition, physica properties, and antioxidant activities of yam flours as affected by different drying methods. Food Chem 83: 85-92.

18. Merlin JC, Statoua A, Brouillard R (1985) Investigation of the in vivo organization of anthocyanins using resonance raman microspectrometry. Phytochemistry 24: $1575-1581$.

19. Merlin JC, Statous A, Cornard JP, Saidi-Idrissi M, Brouillard R (1994) Resonance raman spectroscopic studies of anthocyanins and anthocyanidins in aqueous solutions. Phytochemistry 35: 227-232.

20. Merlin JC, Cornard JP (1994) Vibrational analysis of hydroxyflavylium derivatives by IR, Fourier transform Raman and resonance Raman spectroscopies. Spectrochim Acta A 50: 703-712.

21. Chase B (1987) Fourier transform Raman spectroscopy, Anal Chem 59 881A-889A.

22. Chase BD (1986) Fourier transform Raman spectroscopy. J Am Chem Soc 108: $7485-7488$

23. Chase B (1994) A new generation of Raman instrumentation, Appl Spectrosc 48: 14A-19A.

24. Weng YM, Weng RH, Tzeng CY, Chen W (2003) Structural Analysis of Triacylglycerols and Edible Oils by Near-Infrared Fourier Transform Raman Spectroscopy. Appl Spectrosc 57: 413-418.

25. Schulz H, Baranska M, Baranski R (2005) Potential of NIR-FT-Raman spectroscopy in natural carotenoid analysis. Biopolymers 77: 212-221.

26. Cîntă Pînzaru S, Pavel I, Leopold N, Kiefer W (2004) Identification and characterization of pharmaceuticals using Raman and surface-enhanced Raman scattering. J Raman Spectrosc 35: 338-346.

27. Rösch P, Popp J, Kiefer W (1999) Raman and surface enhanced Raman spectroscopic investigation on Lamiaceae plants. J Mol Struct 480-481: 121 124

28. Schrader B, Klump HH, Schenzel K, Schulz H (1999) Non-destructive NIR FT Raman analysis of plants. J Mol Struct 509: 201-212.

29. Abdel-Aal E-SM, Hucl P (2003) Composition and Stability of Anthocyanins in Blue-Grained Wheat. J Agric Food Chem 51: 2174-2180. 
Citation: Wang CH, Chen MJ, Tseng CY, Wei KM, Chen W (2013) Structural Characterization of Functional Compositions Isolated from Dioscorea Purpurea (Cultivar of Ming-Chien) by Raman Spectroscopy. Nat Prod Chem Res 1: 110. doi:10.4172/ 2329-6836.1000110

30. Abdel-Aal E-SM, Young JC, Rabalski I (2006) Anthocyanin Composition in Black, Blue, Pink, Purple, and Red Cereal Grains. J Agric Food Chem 54: 4696-4704.

31. Fiorini M (1995) Preparative high-performance liquid chromatography for the purification of natural anthocyanins. J Chromatogr 692: 213-219.

32. Philpott M, Gould KS, Lim C, Ferguson LR (2004) In Situ and In Vitro Antioxidant Activity of Sweetpotato Anthocyanins. J Agric Food Chem 52: 1511-1513.

33. Goda Y, Shimizu T, Kato Y, Nakamura M, Maitani T, et al. (1997) Two acylated anthocyanins from purple sweet potato. Phytochemistry 44: 183-186.

34. Harvey PJ, Boulter D (1983) Isolation and characterization of the storage protein of yam tubers (Dioscorea rotundata). Phytochemistry 22: 1687-1693.

35. Laemmli UK (1970) Cleavage of structural proteins during the assembly of the head of bacteriophage T4. Nature 227: 680-685.

36. Yoshida K, Kondo T, Goto T (1991) Unusually stable monoacylated anthocyanin from purple yam dioscorea alata. Tetrahedron Lett 32: 5579-5580.
37. Wang $\mathrm{H}$, Race EJ, Shrikhande AJ (2003) Characterization of Anthocyanins in Grape Juices by Ion Trap Liquid Chromatography-Mass Spectrometry. J Agric Food Chem 51: 1839-1844

38. Christensen TM, Jochimsen BU (1983) Enzymes of Ureide Synthesis in Pea and Soybean. Plant Physiol 72: 56-59.

39. Osuji GO, Ory RL (1986) Purine degradative pathway of the yam and sweet potato. J Agric Food Chem 34: 599-602.

40. Stadelman WJ, Cotterill OJ (1995) Egg science and technology. (4thedn) Haworth Press, New York.

41. Shih S, Weng YM, Chen S, Huang SL, Chen W, et al. (2003) FT-Raman spectroscopic investigation of lens proteins of tilapia treated with dietary vitamin E. Arch Biochem Biophys 420: 79-86.

42. Siamwiza MN, Lord RC, Chen MC, Takamatsu T, Harada I, et al. (1975) Interpretation of the doublet at 850 and $830 \mathrm{~cm}^{-1}$ in the Raman spectra of tyrosyl residues in proteins and certain model compounds. Biochemistry 14: 48704876 . 